\title{
APPLICATION AND VALIDATION OF DERIVATIVE SPECTROPHOTOMETRIC FOR DETERMINATION LEVELS OF TERNARY MIXTURES OF PARACETAMOL, PROPYPHENAZONE, AND CAFFEINE IN TABLET DOSAGE FORM
}

\author{
ARTHA YULIANA SIANIPAR, MUCHLISYAM*, SITI MORIN SINAGA \\ Department of Pharmaceutical Chemistry, Faculty of Pharmacy, Universitas Sumatera Utara, Medan, Indonesia. \\ Email: muchlisyam@usu.ac.id
}

Received: 07 March 2018, Revised and Accepted:25 March 2018

ABSTRACT

Objective: This study was to develop a spectrophotometric method with derivative zero-crossing for determines the levels of paracetamol (PCT), propyphenazone (PRO), and caffeine (CAF) in tablet dosage form without prior separation.

Method: The study begins with optimizing the type of solvent, phosphate buffer (pH 7.2) and a mixture of phosphate buffer (pH 7.2) with methanol at ratio 90:10; 70:30; 50:50; 30:70; and 10:90. Spectrophotometric method with zero-crossing, tested validity based on linearity, accuracy, precision, limit of detection, and limit of quantification. Then, the method applied to determine the levels of PCT, PRO, and CAF in tablet.

Result: The mixture of phosphate buffer (pH 7.2) with methanol at ratio 70:30 can be used for analysis. Applications zero-crossing technique on assay of PCT and CAF performed on the first derivative and $\Delta \lambda 2$ with $\lambda 239.4 \mathrm{~nm}$ for PCT and $\Delta \lambda 8$ with $\lambda 245.6 \mathrm{~nm}$ for CAF while PRO in the third derivative and $\Delta \lambda 8$ with $\lambda 249.6 \mathrm{~nm}$, resulting $100.91 \%, 104.75 \%$, and $103.33 \%$ for levels of PCT, PRO, and CAF, respectively.

Conclusion: Spectrophotometric derivative method with zero-crossing qualified in validation parameters.

Keywords: Paracetamol, Propyphenazone, Caffeine, Derivative spectrophotometry, Zero-crossing, Phosphate buffer (pH 7.2), Methanol.

(c) 2018 The Authors. Published by Innovare Academic Sciences Pvt Ltd. This is an open access article under the CC BY license (http://creativecommons. org/licenses/by/4. 0/) DOI: http://dx.doi.org/10.22159/ajpcr.2018.v11s1.26553

\section{INTRODUCTION}

Most circulating drugs are a combination of several active ingredients, each of which aims to enhance the effects of drug therapy and ease of use [1]. One of the most commonly used mixtures of active substances is paracetamol (PCT), propyphenazone (PRO), and caffeine (CAF) used to treat headache, rheumatism, toothache, migraine, and menstrual pain [2].

In its marketing, the quality inspection of a medical preparation is absolutely necessary to ensure that the preparation of the drug contains the ingredients of predetermined quality and amount and follows standard analytical procedures, thereby promoting the expected therapeutic effect [1].

Literature survey reveals that few high-performance liquid chromatography (HPLC) methods [3,4] have been reported for the estimation of PCT, PRO, and CAF. The results showed that six degradation products contained in the mixture can be detected and determined simultaneously and HPLC method has satisfied good validation requirements, especially with a fast retention time of 3.8; 4.7; and $5.7 \mathrm{~min}$ for PCT, PRO, and CAF, respectively. This makes HPLC method has high analytical sensitivity but requires relatively high cost compared to spectrophotometry [1].

The derivative spectrophotometric method is one of the spectrophotometric methods that can be used to analyze the mixture of several substances directly without having to do separation first though with adjacent wavelengths [5]. Derivative spectrophotometric methods are relatively simple, and operating costs are cheaper compared to HPLC [6].

The zero-crossing method is the most common method used in derivative spectrophotometry, although this method is rarely used for the determination of ternary mixtures with application to higher derivatives, the determination of the levels of ternary mixtures can be performed. This method is faster and simpler. Literature survey reveals that derivative spectrophotometry methods [2] have been reported for the estimation of PCT, PRO, and CAF simultaneously in tablet preparations.

The aim of this study is to develop a simple, precise, and accurate spectrophotometric method for the estimation of PCT, PRO, and CAF in pharmaceutical dosage forms.

\section{METHODS}

Chemical and reagents

All material and reagents were analytical reagent grade. PCT, PRO, and CAF were purchased from National Agency of Drugs and Foods Control Indonesia and Kimia Farma Company.

\section{APPARATUS}

The spectrophotometric measurements were carried out on a Shimadzu UV-1800 spectrophotometer. The absorption spectra were measured using $1 \mathrm{~cm}$ quartz cells. For the derivative method, the absorption spectra were recorded on the same spectrophotometer, with $1 \mathrm{~cm}$ quartz cells and supported with UV-Probe 2.34 software.

\section{Optimization of solvents}

An optimization was performed by measuring the absorbance of PCT, PRO, and $\mathrm{CAF}$ in $\mathrm{HCl} 0.1 \mathrm{~N}$, phosphate buffer $\mathrm{pH} 7.2$, and phosphate buffer mixture pH 7.2 with methanol at a ratio of 90:10; 70; 30; 50:50; 30:70; and 10:90 [7].

\section{Preparation standard solution}

Stock solutions containing $25 \mu \mathrm{g} / \mathrm{mL}$ PCT, $25 \mu \mathrm{g} / \mathrm{mL}$ PRO, and $25 \mu \mathrm{g} / \mathrm{mL}$ CAF were prepared in phosphate buffer mixture $\mathrm{pH} 7.2$ with methanol at a ratio 70:30 (PM 7:3). Further dilutions were done using PM 7:3 as described under construction of calibration graphs.

Construction of calibration graphs

Different aliquots of the standard solution of PCT, PRO, and CAF were transferred into $25 \mathrm{ml}$ volumetric flask. The solutions were then 
completed to the volume with PM 7:3, so the final concentration for PCT was 4.5 ; $5.5 ; 6.5 ; 8.5 ; 9.5$; and $10.5 \mu \mathrm{g} / \mathrm{mL}$, PRO was 8.0 ; 9.5; 11.5 ; 12.5; 14.0 ; and $15.5 \mu \mathrm{g} / \mathrm{mL}$, and CAF was 4.6 ; 6.6; 8.6; 10.6; 12.6; and $14.6 \mu \mathrm{g} / \mathrm{mL}$. The absorption spectrum of each solution was recorded within the wavelength range $200-400 \mathrm{~nm}$ and stored.

\section{Assay of tablet formulation by derivative spectrophotometry}

Twenty commercial tablets were weighed accurately. A powder quantity equivalent to $50 \mathrm{mg}$ PCT was accurately weighed and transferred to volumetric flask of $50 \mathrm{ml}$ capacity. $25 \mathrm{ml} \mathrm{PM} \mathrm{7:3} \mathrm{was} \mathrm{transferred} \mathrm{to} \mathrm{this}$ volumetric flask and sonicated $15 \mathrm{~min}$. The flask was shaken, and the volume was made up to the mark with PM 7:3. The above solution was filtered through Whatman filter paper no. 42 . Pipette $0.16 \mathrm{~mL}$ of filtrate into a $25 \mathrm{~mL}$ volumetric flask, added with $0.48 \mathrm{ml}$ and $1 \mathrm{ml}$ of standard solution of PRO and CAF, respectively, then added with a solvent to the mark line. The absorbance is then measured at $200-400 \mathrm{~nm}$ to obtain absorbance. The quantitation was carried out by keeping these values to the straight line equation of calibration curve.

\section{Method validation}

The proposed method has been extensively validated in terms of linearity, accuracy, and precision. The accuracy of the method was determined by calculating recovery of PCT, PRO, and CAF by the standard addition method.

\section{RESULTS}

\section{Optimization of solvent type}

Phosphate buffer $\mathrm{pH} 7.2, \mathrm{HCl} 0.1 \mathrm{~N}$, and phosphate buffer mixture $\mathrm{pH}$ 7.2 with methanol at a ratio of $90: 10 ; 70 ; 30 ; 50: 50 ; 30: 70$; and 10:90 is the type of solvent that will be optimized. Table 1 shows the value of photometric errors.

\section{The normal absorption spectrum}

Fig. 1 shows the absorption spectra of $6.5 \mu \mathrm{g} / \mathrm{mL}$ PCT, $11.0 \mu \mathrm{g} / \mathrm{mL}$ PRO, and $6.6 \mu \mathrm{g} / \mathrm{mL} \mathrm{CAF}$, and the ternary mixture.

\section{The derivative spectra}

Figs. 2-4 show the derivative spectra of $6.5 \mu \mathrm{g} / \mathrm{mL}$ PCT, $11.0 \mu \mathrm{g} / \mathrm{mL}$ PRO, and $6.6 \mu \mathrm{g} / \mathrm{mL} \mathrm{CAF}$

\section{Method validation}

Table 2 shows the validation parameters for derivative spectrophotometry.

\section{Application of the method in commercial tablet}

The proposed method was applied for the determination of PCT, PRO, and $\mathrm{CAF}$ in their combined commercial tablet and the result is shown in Table 3.

\section{DISCUSSION}

Based on the result of solvent optimization shows that the solvent PM $7: 3$ has the smallest of photometric errors number so the solvent used in this research is PM 7:3.
These results indicate that there is a difference between the results of research conducted by Saraan (2015), which in this study the optimal solvent for the determination of PCT, ibuprofen, and CAF levels is phosphate buffer $\mathrm{pH} 7.2$, while in this study obtained an optimal solvent for determination PCT, PRO, and CAF is PM 7:3. This is because propyphenazone is more soluble in water than ibuprofen so in the presence of methanol will increase the solubility of PRO [7-10].

The absorption spectra of three components are strongly overlapped (Fig. 1) that was sufficiently enough to demonstrate the resolving power of the proposed method. In this respect, different solutions of PCT, PRO, and CAF were prepared in the concentration ranges stated in the construction of calibration graph. The absorption spectra of these concentrations were recorded and stored.

For the determination of PCT, the first derivative the stored spectra of standard solutions of PCT, PRO, and CAF and a solution of their mixture were calculated with $\Delta \lambda 2 \mathrm{~nm}$ (Fig. 2). From this figure, PCT can be determined in this mixture by measuring the amplitude at $239.4 \mathrm{~nm}$ where there is no contribution from PRO and CAF (zero-crossing point of PRO and CAF).

For the determination of PRO, the third derivative the stored spectra of standard solutions of PCT, PRO, and CAF and a solution of their mixture were calculated with $\Delta \lambda 8 \mathrm{~nm}$ (Fig. 3). From this figure, PRO can be determined in this mixture by measuring the amplitude at $249.6 \mathrm{~nm}$ where there is no contribution from PCT and CAF (zero-crossing point of PCT and CAF).

For the determination of CAF, the first derivative the stored spectra of standard solutions of PCT,PRO, and CAF and a solution of their mixture were calculated with $\Delta \lambda 8 \mathrm{~nm}$ (Fig. 4). From this figure, CAF can be determined in this mixture by measuring the amplitude at $245.6 \mathrm{~nm}$ where there is no contribution from PCT and PRO (zero-crossing point of PCT and PRO). The wavelengths $239.4 \mathrm{~nm}, 249.6 \mathrm{~nm}$, and $245.6 \mathrm{~nm}$ in each condition were selected for analysis of PCT, PRO, and CAF, respectively [11-13].

The linearity of the proposed method was evaluated for each drug by analyzing the different concentration of each PCT, PRO, and CAF, within the concentration range in construction calibration graph. The assay was performed according to the previously stated conditions. A straight line was obtained in each case. Analysis of these graphs showed excellent linearity of the calibration graph and agreement to Beer's law.

As shown in Table 2, the resulting mixtures were assayed according to the above-stated procedure, and the results were calculated as the percentage of analyte recovered. Limit of detection and limit of quantification values were indicated that the method shows high sensitivity. The good recovery values assure the high accuracy of the proposed method.

\section{CONCLUSION}

The proposed method provides a simple and accurate quantitative analysis for the determination of PCT, PRO, and CAF as a ternary

Table 1. Photometric errors

\begin{tabular}{|c|c|c|c|c|c|c|c|}
\hline \multirow[t]{2}{*}{ Type of solvent } & \multicolumn{3}{|c|}{ Photometric errors (\%) } & \multicolumn{3}{|c|}{ Reduction with 2.7185 (\%) } & \multirow[t]{2}{*}{ Amount (\%) } \\
\hline & PCT & PRO & CAF & PCT & PRO & CAF & \\
\hline$P$ & 2.7297 & 2.7195 & 2.7280 & 0.0112 & 0.0010 & 0.0095 & 0.0217 \\
\hline PM 3:7 & 2.7715 & 2.7332 & 2.7366 & 0.0530 & 0.0147 & 0.0181 & 0.0858 \\
\hline PM 5:5 & 2.7383 & 2.7178 & 2.7332 & 0.0198 & -0.0007 & 0.0147 & 0.0352 \\
\hline PM 7:3 & 2.7229 & 2.7195 & 2.7178 & 0.0044 & 0.0010 & -0.0007 & 0.0061 \\
\hline PM 9:1 & 2.7212 & 2.7195 & 2.7229 & 0.0027 & 0.0010 & 0.0044 & 0.0081 \\
\hline $\mathrm{HCl} 0.1 \mathrm{~N}$ & 2.7178 & 2.7195 & 2.7610 & 0.0007 & 0.0010 & 0.0425 & 0.0428 \\
\hline
\end{tabular}

P: Phosphate buffer pH 7.2. PM 5:5: phosphate buffer pH 7.2:methanol (50:50). PM 1:9: Phosphate buffer pH 7.2:methanol (10:90). PM 7:3: Phosphate buffer pH 7.2:methanol (70:30). PM 3:7: Phosphate buffer pH 7.2:methanol (30:70). PM 9:1: Phosphate buffer pH 7.2:methanol (90:10). PCT: Paracetamol, PRO: Propyphenazone, CAF: Caffeine 
Table 2: Validation parameters for derivative spectrophotometry

\begin{tabular}{llll}
\hline Parameters & PCT & PRO & CAF \\
\hline Linearity & 0.9960 & 0.9950 & 0.9999 \\
Accuracy (\%) & 99.67 & 101.11 & 101.3 \\
Precision (RSD) (\%) & 1.82 & 1.42 & 0.80 \\
LOD & 1.1531 & 2.0871 & 0.3928 \\
LOQ & 3.4942 & 6.3246 & 1.1902 \\
\hline
\end{tabular}

LOD: Limit of detection, LOQ: Limit of quantification, PCT: Paracetamol, PRO: Propyphenazone, CAF: Caffeine, RSD: Relative standard deviation

Table 3: Result of quantification of PCT, PRO, and CAF in marketed formulation by derivative spectrophotometry method

\begin{tabular}{lll}
\hline Drug & Label claim (mg/tablet) & Amount found (mg/tablet \\
\hline PCT & 350 & $100.91 \%$ \\
PRO & 150 & $104.75 \%$ \\
CAF & 50 & $103.33 \%$ \\
\hline
\end{tabular}

PCT: Paracetamol, PRO: Propyphenazone, CAF: Caffeine,

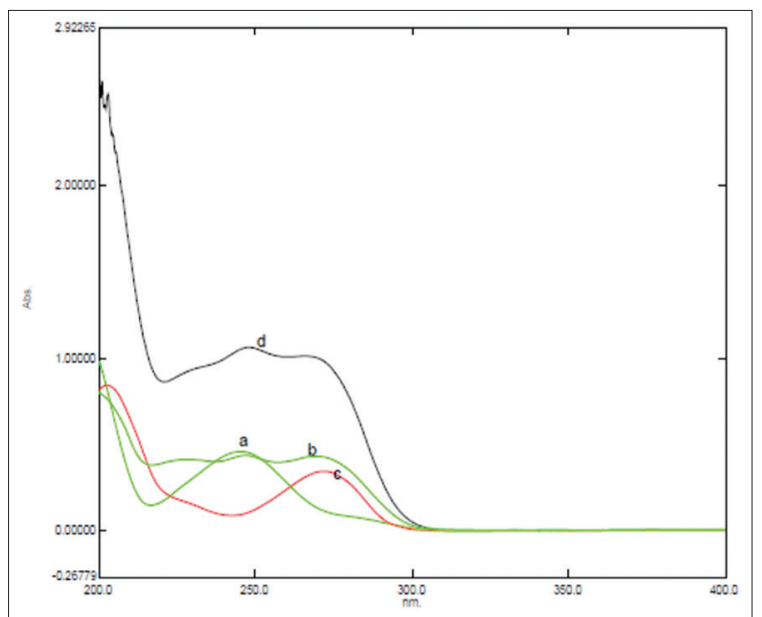

Fig. 1. Absorption spectra of (a) $6.5 \mu \mathrm{g} / \mathrm{mL}$ paracetamol, (b) $11.0 \mu \mathrm{g} / \mathrm{mL}$ propyphenazone, (c) $6.6 \mu \mathrm{g} / \mathrm{mL}$ caffeine, (d) the ternary mixture

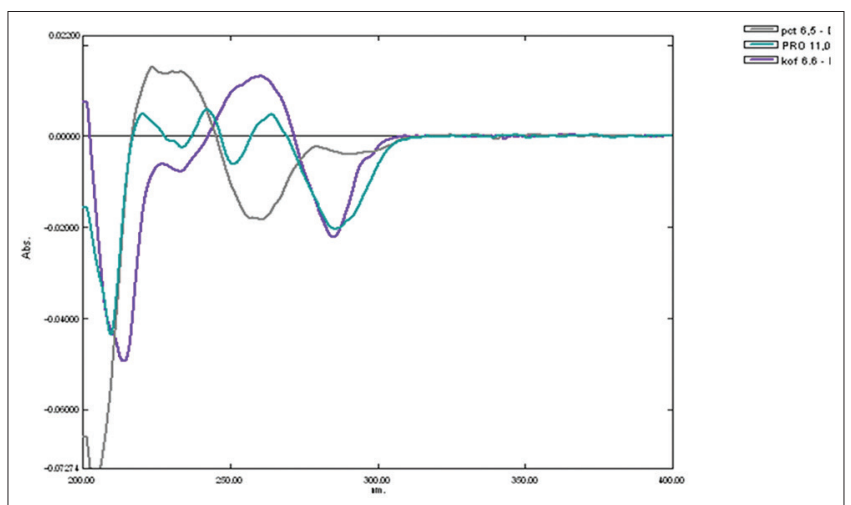

Fig. 2: First derivative spectra were calculated with $\Delta \lambda 2 \mathrm{~nm}$

mixture. The proposed method is simple as there is no need for solvent extraction and direct as it estimates each component independent of the other, and also the method is rapid, low cost, and harmless to the environment. Hence, it could be applied in quality control laboratories.

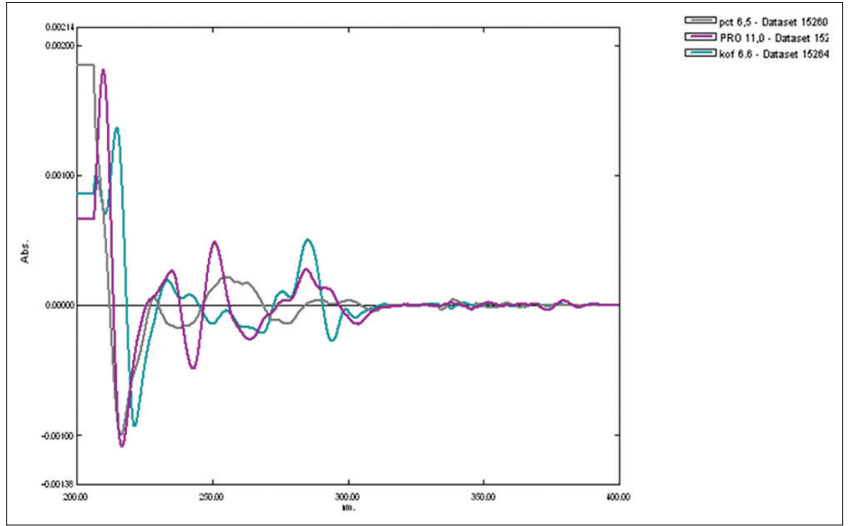

Fig. 3: Third derivative spectra were calculated with $\Delta \lambda 8 \mathrm{~nm}$

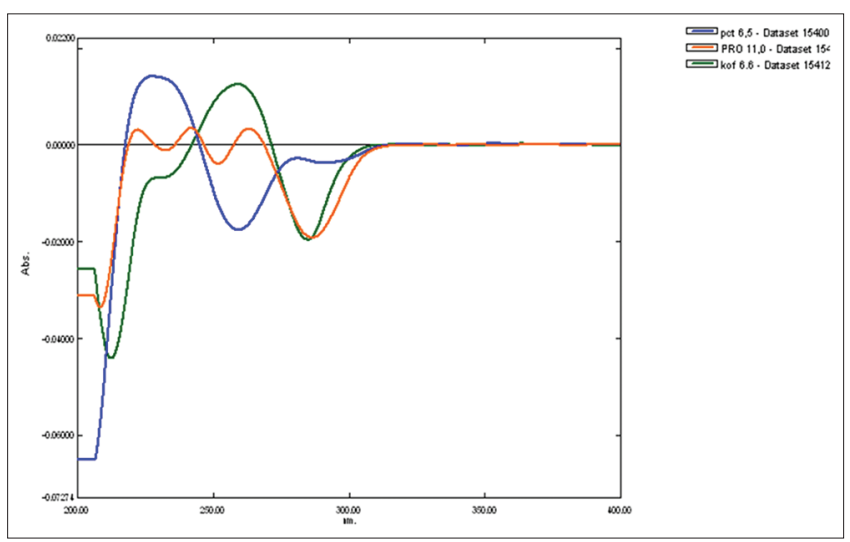

Fig. 4: First derivative spectra were calculated with $\Delta \lambda 8 \mathrm{~nm}$

\section{REFERENCES}

1. Vichare V, Mujgond P, Tambe V, Dhole SN. Simultaneous Spectrophotometric determination of paracetamol and caffeine in tablet formulation. Int J Pharm Tech Res 2010;2:2512-6.

2. Delvadiya K, Ritu K, Prachi K, Sunil K, Pratik P. Spectrophotometric simultaneous analysis of paracetamol, propyphenazone and caffeine in tablet dosage forms. Int J Pharm Pharm Sci 2011;3:170.

3. Adupa S, Sr A, Simhadri H, Kalidindi SV. Simultaneous estimation of paracetamol caffiene and propyphenazone in bulk and pharmaceutical dosage form by RP-HPLC. J Pharm Res 2014;8:331-5.

4. Soponar F, Staniloae D, Moise G, Szaniszlo B, David V. Simultan determination of paracetamol, propyphenazone and caffeine from pharmaceutical preparation in the presence of related substances using a validated HPLC - DAD method. Rev Roum Chim 2013;58:433-40.

5. El-Sayed AA, El-Salem NA. Recent development of derivative spectrophotometry and their analytical applications. Anal Sci 2005;21:595-614.

6. Özgür MÜ, Ikbal K. Determination of ternary mixtures of vitamins (B1, B6, B12) by zero-crossing derivative spectrophotometry. Turk J Chem 2002;26:385-91.

7. Saraan SM, Sinaga SM, Muchlisyam M. Development method for determination of ternary mixture of paracetamol, ibuprofen and caffeine in tablet dosage form using zero-crossing derivative spectrophotometric. Int J Pharm Tech Res 2015;7:349-53.

8. Health Department of Republic of Indonesia. Indonesian Pharmacopoeia. $4^{\text {th }}$ ed. Indonesian: General Directory of Drug and Food Control; 1995.

9. Dinc E, Kökdil G, Onur F. Derivative ratio spectra-zero crossing spectrophotometry and LC method applied to the quantitative determination of paracetamol, propyphenazone and caffeine in ternary mixtures. J Pharm Biomed Anal 2001;26:769-78.

10. Hajian R, Afshari N. The spectrophotometric multicomponent analysis of ternary mixture of ibuprofen, caffeine and parasetamol by the combination of double divisor-ratio spectra derivative and h-point standard addition method. E J Chem 2012;9:1154-5. 
11. Abdel-Hay M, Azza AG, Ekran MH, Tarek SB. Derivative and derivative ratio spectrophotometric analysis of antihypertensive ternary mixture of amiloride hydrochloride, hydrochlorthiazide and timolol maleate. J Chin Chem Soc 2008:55:971-8.

12. Nejal MB, Chavada VD, Sanyal M, Shrivastav PS. Manipulating ratio spectra for the spectrophotometric analysis of diclofenac sodium and pantoprazole sodium in laboratory mixtures and tablet formulation. Sci World J 2014;2014:1-10.

13. Popović GV, Lidija BP, Violeta MS. Analytical application of derivative spectrophotometry. J Serb Chem Soc 1999;65:464. 